\title{
Association of Vitamin D Receptor BsmI Gene Polymorphism with BMD Z-Score in Iranian Children and Adolescents (9 - 18 Years Old)
}

\author{
Nima Montazeri-Najafabady ${ }^{1}$, Mohammad Hossein Dabbaghmanesh ${ }^{1,{ }^{*}}$, Rajee Mohammadian Amiri ${ }^{1}$ \\ and Mahdi Akbarzadeh ${ }^{2}$ \\ ${ }^{1}$ Endocrinology and Metabolism Research Center, Nemazee Hospital, Shiraz University of Medical Sciences, Shiraz, Iran \\ ${ }^{2}$ Cellular and Molecular Research Center, Research Institute for Endocrine Sciences, Shahid Beheshti University of Medical Sciences, Tehran, Iran \\ "Corresponding author: Endocrinology and Metabolism Research Center, Nemazee Hospital, Shiraz University of Medical Sciences, Shiraz, Iran. Email: dabbaghm@sums.ac.ir
}

Received 2018 July 29; Revised 2019 February 06; Accepted 2019 April 09.

\begin{abstract}
Background: The vitamin D receptor(VDR) gene variants are known as the main risk factor for low bone mass.

Objectives: In this study, the association of vitamin D receptor genetic variants, BsmI (rs1544410) and FokI (rs2228570), with bone mass in Iranian children and adolescents, was evaluated.

Methods: The study population comprised of children and adolescents aged between 9 to 18 years (FokI: 123 boys and 120 girls, BsmI: 108 boys and 110 girls). Vitamin D, calcium, phosphorus, total cholesterol (TC), High-density lipoprotein-cholesterol (HDL-C) and triglyceride (TG) concentrations were assayed. Bone mineral density and body composition parameters were measured by the Hologic system DXA. BMD Z-score $\leq-2$ was considered as low bone density for chronologic age. PCR-restriction fragment length polymorphism was done for genotyping of BsmI and FokI polymorphisms. The association between VDR variants and bone mineral density was investigated using logistic regression analysis.

Results: No significant differences in body composition and biochemical parameters were detected among the evaluated VDR genotypes. For VDR BsmI, the mean values for Z-score of the lumbar spine, neck, inter and total femur was greater in the bb genotype compared to BB and Bb genotypes. Logistic regression analysis revealed a significant association between femoral neck Z-score and VDR BsmI genotypes in an additive genetic model (unadjusted model ( $\mathrm{P}=0.035$; $\mathrm{Bb}$ vs. $\mathrm{bb}$ ), model 1 (adjusted for age and sex, $\mathrm{P}=$ 0.021 ; $\mathrm{Bb}$ vs. $\mathrm{bb}$ ), model 2 (adjusted for age, sex and $\mathrm{BMI}, \mathrm{P}=0.013$; $\mathrm{Bb}$ vs. bb) and model 3 (adjusted for age, sex, BMI and puberty, $\mathrm{P}=$ 0.011 ; Bb vs. bb, $\mathrm{P}=0.049$; BB vs. bb)) and dominant genetic model ((unadjusted model, $\mathrm{P}=0.033$; $\mathrm{BB}+\mathrm{Bb}$ vs. bb), model 1 (adjusted for age and sex, $\mathrm{P}=0.023$; $\mathrm{BB}+\mathrm{Bb}$ vs. $\mathrm{bb}$ ), model 2 (adjusted for age, sex and $\mathrm{BMI}, \mathrm{P}=0.012 ; \mathrm{BB}+\mathrm{Bb}$ vs. bb and model 3 (adjusted for age, sex, BMI and puberty, $\mathrm{P}=0.012 ; \mathrm{BB}+\mathrm{Bb}$ vs. $\mathrm{bb})$ ).

Conclusions: This investigation indicated that VDR BsmI polymorphism may be associated with BMD Z-score of the femoral neck but not the lumbar spine, in Iranian children and adolescents.
\end{abstract}

Keywords: Vitamin D Receptor, RFLP, Bone Mineral Density, Children

\section{Background}

Childhood and adolescence are important periods for bone growth in life, and deficiencies in the bone mass achieved in early life may lead to the development of osteoporosis in later life (1). Various factors such as calcium consumption, physical activity, body mass, and genetic factors can influence the peak bone mass in childhood (2). The vitamin $\mathrm{D}$ receptor (VDR) is known as a key genetic factor in discovering the risk of low bone mass and osteoporosis (3).

The VDR and its biologically active ligand, 1-alpha, 25dihydroxyvitamin D3 (calcitriol), act together to conduct various types of biological processes, through interaction with response elements in target genes (4). This receptorligand complex plays a key role in bone formation and resorption by stimulating osteoblasts, osteoclasts, and calcium homeostasis. According to the multi-aspect role of VDR in biological pathways, genetic variations (polymorphism) in VDR sequences could be the leading cause of gene activation failure which affects the bone metabolism (4).

Several polymorphic regions of the VDR gene: BsmI, ApaI, FokI, TruI, EcoRV, Cdx2, have been validated in different populations such as postmenopausal Italian woman (5), Japanese girls (6), and healthy Caucasian men (7).

In the Iranian population, there are a few studies on adults, in which the association of VDR polymorphisms 
with osteoporosis and bone mineral density were investigated. Dabirnia et al. evaluated the association of vitamin D receptor polymorphisms, TaqI (rs731236) and ApaI (rs7975232), with osteoporosis in menopausal Azari women of the Zanjan province (8). In another study, the link between ApaI, TaqI, BsmI variants of the vitamin D receptor gene and bone parameters in women aged 45 years and above, in southwestern Iran was evaluated (9). Furthermore, Mohammadi et al. investigated the effect of VDR polymorphisms (Fok1) (rs2228570) on bone mineral density, in the Kurdistan population (10). Fok1 and BsmI (rs1544410) single nucleotide polymorphisms (SNPs) have been widely studied, and the association of these polymorphic loci with bone mineral density (BMD) has also been investigated (11). Even though practical data have been indecisive for BsmI, few studies have revealed significant associations between BsmI and osteoporosis (12-16). Also, there are only a few studies on the effect of BsmI on BMD in healthy children and adolescents $(17,18)$. Ames et al. found a great association between FokI, calcium absorption and whole body BMD in a cross-sectional study on children aged 7 - 12 years (2).

The VDR FokI polymorphism occurs at the start codon of the VDR gene. Wild allele (F) leads to production of full length protein of 427 amino acids while mutant alleles (f) code shorter VDR proteins which are more active than the longer isoform $(4,11)$. The VDR FokI polymorphism may also have an impact on BMD, through alterations in calcium absorption (3).

The VDR BsmI polymorphism is located in the intronic region (intron 8 near the 3'end). It is thought to affect VDR translational activity due to its strong linkage disequilibrium with a poly adenosine (poly (A)) microsatellite repeat in the 3'untranslated region (19). In addition to vitamin D levels, the BsmI polymorphism has also been shown to be associated with obesity, insulin resistance and type 2 diabetes in some populations (19).

So far, it has not been precisely identified whether VDR genotypes have positive or negative effects on bone mass achievement and bone loss (20), and further in-depth studies are needed to uncover the truth. Also, most of the studies assessing the correlation between VDR and bone mineral density have been accomplished in pre- and postmenopausal women and older age (21). Furthermore, gender and ethnicity are important factors that influence osteoporosis and bone mineral density (12).

\section{Objectives}

Ethnic differences in VDR genotype are one of the reasons which explain the ethnic differences in BMD. Thus, due to the critical role of VDR in bone metabolism (5); the limited data on the association between VDR and BMD, in healthy children and adolescents; and also, the controversial results; we aimed to evaluate the association between VDR(BsmI and FokI) gene variants and BMD in healthy children and adolescents from the Iranian population.

\section{Methods}

\subsection{Study Population}

The study population comprised of 250 children and adolescents aged between 9 to18 years, 127 boys and 123 girls, who were picked from Kawar (an urban area located $50 \mathrm{~km}$ east of Shiraz, the central city of Fars province in the south of Iran), using the age-stratified systematic sample. In the present cross-sectional investigation, the participants were randomly selected and enrolled for genotype analysis. Children and adolescents with systemic impairment (e.g. thyroid complications, diabetes, renal problems, adrenal deficiency), history of developed postponed puberty, using any medications (e.g. anticonvulsants or steroids), were omitted from the study. Our study was accepted by the Ethics Committee of Shiraz University of Medical Sciences. An informed consent was obtained from participants and their parents.

\subsection{Blood Collection, DNA Extraction and Genotyping}

All the fasting blood samples were collected and stored in Shiraz Endocrinology Research Center. Genomic DNA was obtained from the blood samples, using the QIAamp blood kit (Qiagen, Hilden, Germany). The VDR gene allelic variants were identified by polymerase chain reactionrestriction fragment length (PCR-RFLP).

PCR amplification was performed using the following primers: For FokI, forward 5'GCACTGACTCTGGCTCTGAC 3'; reverse 5'ACAGCAACCTCAGGAAAGCGA 3' and for BsmI, forward 5'TGAAGGGAGACGTAGCAA 3'; reverse 5'ACCTCATCACCGACATCA 3'. Conditions of the thermocycler were $94^{\circ} \mathrm{C}$ for $5 \mathrm{~min}$; followed by thirty cycles of $94^{\circ} \mathrm{C}$ for $30 \mathrm{~s}$; 58 and $51^{\circ} \mathrm{C}$ for FokI and BsmI, respectively, for $1 \mathrm{~min}$; and $72^{\circ} \mathrm{C}$ for $30 \mathrm{~s}$. After PCR, RFLP was performed by FokI and BsmI restriction enzymes. Digested PCR outcomes were determined on $2 \%$ agarose gel and detected by a UV transilluminator.

\subsection{Anthropometric Measurements and Tanner Stages}

Anthropometric parameters including body height and weight of the participants were measured using a wallmounted meter and standard scale (Seca, Germany), respectively. Height was measured to the nearest $0.5 \mathrm{~cm}$ and 
weight to the nearest $0.1 \mathrm{~kg}$. Waist circumference was evaluated at the level of the umbilicus to the nearest millimeter. Body mass index (BMI) was defined as weight (kg) divided by square of height $\left(\mathrm{m}^{2}\right)$. Pubertal stage of the children and adolescents was determined by an endocrinologist, through quantifying the bone mass by dual-energy X-ray absorptiometry (DXA) (22). Pubertal stage was assessed according to the Tanner standard classification, during the visit for Dual-energy X-ray absorptiometry (DEXA) scan. Children and adolescents with Tanner stage of 1 were defined as pre-pubertal, 2 and 3 as early pubertal, and those with stages 4 and 5 were categorized as pubertal.

\subsection{Biochemical Parameters}

Blood samples were collected in Shiraz Endocrinology Research Center, after overnight fasting. Serum levels of total cholesterol (TC), high-density lipoprotein-cholesterol (HDL-C), triglyceride (TG), calcium, and phosphorous were quantified by enzymatic reagents (Biosystems, Barcelona, Spain), using an A-25 Biosystem Autoanalyser with a standard automated technique. The concentration of 25hydroxy vitamin D (25OHVitD) was measured by highperformance liquid chromatography (HPLC) (Young Lee 9100, South Korea) in ng/mL. Low-density lipoprotein(LDL) concentrations were calculated from the quantified levels of TG, HDL-c, and TC according to the Friedewald equation. Non-HDL-C was calculated by subtracting HDL-C from total cholesterol. The factor of variance (CV\%) for TG, TC, and HDL methods was $1.7 \%-2.6 \%, 1 \%-1.9 .5 \%$, and $1.3 \%-1.5 \%$, correspondingly.

\subsection{Bone Mineral Density Measurements}

The Hologic system DXA (Discovery QDR, USA) was applied to quantify BMD $\left(\mathrm{g} / \mathrm{cm}^{2}\right)$, bone mineral content (BMC) in grams, and bone area (BA) in square centimeters. The coefficients of variation for the femoral neck, lumbar spine, and total body (created on the quantities in ten children and adolescents) were $2.4 \%, 0.51 \%$, and $1 \%$, respectively. Total body without the head (subtotal) that consisted of arms, ribs, spine, pelvis, and legs of both right and left sides; total spinal measures consisting within L1, L2, L3 and L4; and total femoral measures including the neck, trochanteric, and intertrochanteric; were demonstrated in BA $\left(\mathrm{cm}^{2}\right)$, BMC $(\mathrm{g})$ and BMD $\left(\mathrm{g} / \mathrm{cm}^{2}\right)$. Larger bones had a higher areal BMD, due to their larger width. Predictable volumetric BMAD was measured for both the lumbar spine (LSBMAD), and femoral neck (FNBMAD) as defined in the calculations below:

LSBMAD = BMC of L2 - L4/area ${ }^{1.5}$

FNBMAD $=$ BMC of femoral neck/area ${ }^{2}$

According to the International Society for Clinical Densitometry (ISCD) guideline, Z-score values were distributed among the two groups: a Z-score of $\mathbf{- 2 . 0}$ or lower was described as "Low BMD for chronological age", and above 2.0 as "Normal BMD for chronological age" (23). Total body composition was presented as fat mass (g), lean mass (g), lean+BMC ( $\mathrm{g})$, and total mass $(\mathrm{g})$.

\subsection{Statistical Analysis}

IBM $^{\odot}$ SPSS $^{\odot}$ Statistics V. 22.0 for Windows was applied for obtaining all statistical outcomes. Continuous variables were expressed as mean \pm standard deviation (SD).

Children and adolescents' height, weight, age, BMI, and biochemical parameters (TC, LDL, Non-HDL, HDL, and TG) were tested for normal distribution by the Kolmogorov-Smirnov test. Chi-square test was used to evaluate the differences between grouped variables. The chisquare goodness of fit test was applied to assess the HardyWeinberg equilibrium. In addition, genotype and allele frequencies were calculated using chi-square.

Analysis of covariance (ANCOVA) test was employed for evaluating the differences between the VDR polymorphisms, and biochemical and demographic parameters adjusted for age and sex. Logistic regression analysis was used to observe the association between VDR polymorphisms and lumbar spine and, neck Z-scores, under additive, dominant and recessive genetic models adjusted for age, sex, BMI, and puberty, in 3 statistical models. Model 1 was adjusted for age and sex, Model 2 for age, sex and BMI; and Model 3 for age, sex, BMI and the Tanner stage of puberty. Linear regression was performed to evaluate the possible impact of VDR genetic variations on BMD. The minor allele for each SNP was considered as the reference allele. $P$ values less than 0.05 reflect statistically significant results.

\section{Results}

\subsection{Basic Characteristics}

General, clinical and biochemical features of the studied population are presented in Table1. There was no significant variance $(\mathrm{P}>0.05)$ regarding age, $\mathrm{BMI}$, waist circumferences and phosphorus concentration between girls and boys; while weight, height, vitamin $\mathrm{D}$ and calcium levels were significantly higher in boys than girls $(\mathrm{P}<0.05)$.

\subsection{Genotype Frequencies and Distribution of VDR Polymor- phisms}

Genotype counts and frequencies of the VDR polymorphism are presented in Table 2. Genotype and allele frequencies of the studied VDR gene polymorphic sites were in agreement with the Hardy-Weinberg equilibrium ( $\mathrm{P}>$ $0.05)$. 
Table 1. General, Clinical and Biochemical Characteristics in Our Studied Population $^{\mathrm{a}}$

\begin{tabular}{lccc}
\hline Data & Girls, $\mathbf{N}=\mathbf{1 2 3}$ & Boys, $\mathbf{N}=\mathbf{1 2 7}$ & PValue $^{\text {b }}$ \\
\hline Age, $\mathbf{y}$ & $13.5 \pm 2.9$ & $13.75 \pm 2.7$ & 0.632 \\
\hline Weight, kg & $39.4 \pm 11.7$ & $44.7 \pm 14.9$ & $0.001^{\mathrm{b}}$ \\
\hline Height, cm & $148.8 \pm 12.1$ & $157.4 \pm 16.2$ & $0.001^{\mathrm{b}}$ \\
\hline BMI, kg/cm & & $17.5 \pm 3.1$ & 0.797 \\
\hline BMD Z-score & $17.4 \pm 3.2$ & $-0.68 \pm 0.3$ & 0.60 \\
\hline Waist circumference, cm & $68.1 \pm 10.3$ & $67.7 \pm 10.7$ & 0.775 \\
\hline 25OH vit D, ng/mL & $14.1 \pm 5.2$ & $16.1 \pm 5.9$ & $0.004^{\mathrm{b}}$ \\
\hline Calcium, mg/dL & $9.8 \pm 0.4$ & $9.9 \pm 0.5$ & $0.027^{\mathrm{b}}$ \\
\hline Phosphorus, $\mathbf{m g} / \mathbf{d L}$ & $4.1 \pm 0.5$ & $4.1 \pm 1.1$ & 0.816 \\
\hline
\end{tabular}

Abbreviations: BMI, body mass index; BMD, bone mineral density.

${ }^{\text {a }}$ Values are expressed as mean $\pm \mathrm{SD}$.

${ }^{\mathrm{b}}$ Significant at $\% 5$.

For FokI 243 children and adolescents (123 boys and 120 girls) were successfully genotyped.The allele frequency of the VDR FokI polymorphism was $79.6 \%$ for F allele $(\mathrm{n}=387)$ and $20.4 \%$ for $\mathrm{f}$ allele $(\mathrm{n}=99)$.

For BsmI, 218 children and adolescents (108 boys and 110 girls) were successfully genotyped. The allele frequency of the VDR BsmI polymorphism was $44 \%$ for B allele ( $\mathrm{n}=$ 192 ) and $56 \%$ for b allele $(n=244)$.

\subsection{Effect of VDR Polymorphisms on General and Biochemical Parameters}

For FokI, the means \pm SD of height, weight, BMI, serum $250 H V i t D$, serum calcium and serum phosphorus in the studied population (243 subjects), were $153.43 \pm 15 \mathrm{~cm}$, $42.60 \pm 13.78 \mathrm{~kg}, 17.34 \pm 3.1 \mathrm{~kg} / \mathrm{m}^{2}, 15.09 \pm 5.75 \mathrm{ng} / \mathrm{dL}, 9.8$ $\pm 0.5 \mathrm{mg} / \mathrm{dL}$ and $4.07 \pm 0.87 \mathrm{mg} / \mathrm{dL}$, respectively. No significant variances were observed in the means of height, weight, BMI, vitamin D, calcium, and phosphorus serum levels, between FokI genotype groups.

For BsmI, the means \pm SD of height, weight, BMI, serum 25OHVitD, calcium and phosphorus in the studied population (218 subjects) were $152.41 \pm 14.86 \mathrm{~cm}, 41.35 \pm 13.36$ $\mathrm{kg}, 17.61 \pm 3.2,15.09 \pm 5.54 \mathrm{ng} / \mathrm{dL}, 9.8 \pm 0.49 \mathrm{mg} / \mathrm{dL}$, and $4.1 \pm 0.89 \mathrm{mg} / \mathrm{dL}$, respectively. There were no significant variances in the means of BMI, weight, height, vitamin D, calcium, and phosphorus levels, between BsmI genotype groups. The data are summarized in Table 3.

\subsection{Effect of VDR Polymorphisms on Body Composition and DXA Bone Densitometry}

The effect of VDR polymorphisms (FokI and BsmI) on body composition and DXA bone densitometry outputs were analyzed. No significant association was observed between VDR polymorphisms (FokI and BsmI), and total fat mass, total lean+BMC, total fat (\%), total lean mass, and total body mass. In addition, there was no significant association between VDR FokI and BMD, area and BMAD of the lumbar spine, femur and total body without the head. For VDR BsmI, similar observations were obtained. In addition, analysis of variance (ANOVA) results did not show any significant association between VDR polymorphisms and lumbar spine Z-score, neck, intertrochanteric and total femur Z-scores.

4.5. Effect of VDR Polymorphisms on Bone Mineral Density ZScore

The effect of VDR polymorphisms (FokI and BsmI) on BMD Z-score of the categorized groups in three genetic models (additive, dominant and recessive) is presented in Table 4. Multivariate logistic regression analysis results demonstrated no significant association between genotype groups of VDR FokI polymorphisms and Z-scores of the lumbar spine and femoral neck, in low and normal groups, under all studied genetic models. Unlike FokI, VDR BsmI genotypes showed a significant association with femoral neck Z-score under the additive and dominant genetic models. Under additive genetic model, with and without adjustment for different confounders there was a significant increased risk for low femoral neck Z-score for $\mathrm{Bb}$ genotype. Under a dominant genetic model $(\mathrm{BB}+\mathrm{Bb}) \mathrm{vs}$. $\mathrm{bb}$, we found a significant association between VDR BsmI polymorphisms and neck Z-scores under an unadjusted model $(\mathrm{P}=0.033$, OR $(95 \% \mathrm{CI})=3.3(1.5-6))$, model $1(\mathrm{P}=$ 0.023, OR $(95 \% \mathrm{CI})=2.7(1.1-6.2))$, model $2(\mathrm{P}=0.012, \mathrm{OR}$ $(95 \% \mathrm{CI})=3.2(1.2-8))$ and model $3(\mathrm{P}=0.012$, OR $(95 \% \mathrm{CI})$ $=3.5(1.3-9.3)$ ). Considering the significant associated risk with $\mathrm{Bb}$ genotype (under additive model) and $\mathrm{BB}+\mathrm{Bb}$ genotypes (under dominant model) we tested the over dominate model to reveal the probable significant role of $\mathrm{Bb}$ genotype in increasing the risk of low femoral neck Z-score. Results showed marginal significance in adjusted models, result in favor of suggesting B allele as the risk allele.

The R square for logistic regression analysis was about $80 \%$. It seems that the selected independent variables had a major impact on the dependent variables compared to the other unselected variables. In addition, linear regression was done to assess the possible impact of VDR genetic variations on BMD. No significant association was detected between VDR genetic variations and lumbar spine-BMD and femoral neck-BMD (Table 5). 


\begin{tabular}{|c|c|c|c|c|c|c|c|c|}
\hline \multirow[t]{2}{*}{ Sex } & \multicolumn{4}{|c|}{ FokI $(\operatorname{rs2228570}), N=243^{b}$} & \multicolumn{4}{|c|}{$\operatorname{BsmI}(\operatorname{rs1544410}), N=218^{c}$} \\
\hline & $\mathbf{F F}$ & Ff & ff & Total & BB & $\mathbf{B b}$ & $\mathbf{b}$ & Total \\
\hline \multicolumn{9}{|l|}{ Genotype } \\
\hline Boys & $83(67.5)$ & $38(30.9)$ & $2(1.6)$ & 123 & $20(18.5)$ & $55(50.9)$ & $33(30.6)$ & 108 \\
\hline Girls & $73(60.8)$ & $37(30.9)$ & $10(8.3)$ & 120 & $24(21.8)$ & $49(44.5)$ & $37(3.6)$ & 110 \\
\hline \multirow[t]{2}{*}{ All Subjects } & $156(64.2)$ & $75(30.9)$ & $12(4.9)$ & 243 & $44(20.2)$ & $104(47.7)$ & $70(32.1)$ & 218 \\
\hline & $\mathbf{F}$ & f & & Total & B & $\mathbf{b}$ & & Total \\
\hline \multicolumn{9}{|l|}{ Allele } \\
\hline Boys & $204(82.9)$ & $42(17.1)$ & & 246 & $95(44)$ & $121(56)$ & & 216 \\
\hline Girls & $183(76.2)$ & $57(23.3)$ & & 240 & $97(44)$ & $123(56)$ & & 220 \\
\hline All Subjects & $387(79.6)$ & $99(10.4)$ & & 486 & $192(44)$ & $244(56)$ & & 436 \\
\hline \multicolumn{9}{|c|}{$\begin{array}{l}\text { a Values are expressed as No. (\%). } \\
\text { b } \text { Hardy-Weinberg equilibrium for FokI }(\mathrm{P}=0.44) \\
{ }^{\mathrm{c}} \text { Hardy-Weinberg equilibrium for } \mathrm{BsmI}(\mathrm{P}=0.63)\end{array}$} \\
\hline
\end{tabular}

Table 3. Effect of the VDR Polymorphism on Demographic and Biochemical Parameters in Our Studied Population ${ }^{\mathrm{a}}$

\begin{tabular}{|c|c|c|c|c|c|c|c|c|}
\hline \multirow{3}{*}{ Data } & \multicolumn{8}{|c|}{ Genotype } \\
\hline & \multicolumn{4}{|c|}{ FokI $($ rs2228570 $), N=243$} & \multicolumn{4}{|c|}{ BsmI (rs1544410), N = 218} \\
\hline & FF & Ff & ff & PValue & BB & $\mathbf{B b}$ & bb & P Value \\
\hline Height, cm & $152.95 \pm 15.11$ & $155.89 \pm 14.59$ & $144.25 \pm 13.30$ & 0.15 & $152.88 \pm 15.75$ & $151.43 \pm 14.48$ & $153.56 \pm 15$ & 0.17 \\
\hline Weight, Kg & $42.75 \pm 14.34$ & $43.33 \pm 12.88$ & $36 \pm 10.72$ & 0.12 & $41.30 \pm 12.83$ & $40.41 \pm 11.93$ & $42.79 \pm 15.58$ & 0.26 \\
\hline BMI, $\mathbf{k g} / \mathrm{cm}^{2}$ & $17.76 \pm 3.43$ & $17.41 \pm 2.82$ & $16.93 \pm 2.43$ & 0.09 & $17.21 \pm 2.56$ & $17.25 \pm 2.92$ & $17.56 \pm 3.68$ & 0.87 \\
\hline $250 H$ vit $D, n g / m L$ & $14.95 \pm 5.93$ & $15.84 \pm 5.49$ & $12.22 \pm 4.12$ & 0.15 & $14.58 \pm 4.60$ & $15.15 \pm 6.15$ & $15.31 \pm 5.19$ & 0.76 \\
\hline Calcium, mg/dL & $9.84 \pm 0.47$ & $9.90 \pm 0.57$ & $9.78 \pm 0.36$ & 0.62 & $9.77 \pm 0.42$ & $9.88 \pm 0.49$ & $9.79 \pm 0.52$ & 0.40 \\
\hline Phosphorus, mg/dL & $4.04 \pm 0.53$ & $4.11 \pm 1.36$ & $4.19 \pm 0.47$ & 0.53 & $4.14 \pm 0.47$ & $4.18 \pm 1.18$ & $4.00 \pm 0.53$ & 0.46 \\
\hline
\end{tabular}

Abbreviation: BMI, body mass index.

${ }^{\mathrm{a}}$ Values are expressed as mean $\pm \mathrm{SD}$.

\section{Discussion}

In the current study, the influence of VDR gene polymorphisms (FokI(rs2228570) and BsmI(rs1544410)) on biochemical parameters, body composition, BMD and BMD Z-score in Iranian children and adolescents was investigated. A significant association was observed between VDR BsmI and BMD Z-score, while no significant association was found between VDR gene polymorphisms (FokI and BsmI) and biochemical parameters, body composition, and BMD. Also, VDR FokI did not show any significant effect on BMD Zscore. We found that Bb genotype and B allele of VDR BsmI are associated with low BMD compared to bb genotype and $\mathrm{b}$ allele, respectively.

Bone mass and body composition achievements in children and adolescents are affected by factors such as weight, height, hormonal status, and lifestyle features (exercise and calcium consumption), some of which might be under the control of genetic factors $(21,24)$. Finding genetic determinants that influence BMD, might be a useful approach in preventive medicine for identifying individuals at the risk of osteoporosis (21).

Most previous studies on the correlation between VDR and BMD were conducted on twin pairs, pre and postmenopausal women, elderly women, healthy women and in women with osteoporosis or even comparing black and white women (5, 6, 17, 25-27) Also, these investigations have been performed on different ethnic groups, such as Caucasian, British, Italian, Finnish and North American (4, 7, 27,28 ).

In the present study, no significant association was observed between BMD, area, and BMAD (total body without the head, lumbar spine and femur) and VDR FokI, in healthy Iranian children and adolescents. The mean values of BMD, area, and BMAD were higher in the Ff genotype compared to ff and FF genotypes, but it was not sta- 


\begin{tabular}{|c|c|c|c|c|c|c|c|c|}
\hline Data & $\begin{array}{l}\text { Unadjusted OR } \\
(95 \% \mathrm{CI})\end{array}$ & P Value & $\begin{array}{c}\text { Model 1 OR }(95 \% \\
\text { CI })\end{array}$ & P Value & $\begin{array}{c}\text { Model } 2 \text { OR }(95 \% \\
\text { CI })\end{array}$ & P Value & $\begin{array}{c}\text { Model } 3 \text { OR }(95 \% \\
\text { CI })\end{array}$ & P Value \\
\hline \multicolumn{9}{|c|}{ FolkI, $N=243$} \\
\hline \multicolumn{9}{|l|}{ Lumbar spine } \\
\hline \multicolumn{9}{|l|}{ Additive } \\
\hline FF & $0.34(0.86-1.4)$ & 0.10 & $0.35(0.86-1.4)$ & 0.15 & $0.25(0.05-1.1)$ & 0.07 & $0.37(0.07-2)$ & 0.25 \\
\hline $\mathrm{Ff}$ & $0.32(0.86-1.2)$ & 0.133 & $0.32(0.83-1.2)$ & 0.10 & $0.30(0.07-1.2)$ & 0.10 & $0.43(0.09-2.1)$ & 0.30 \\
\hline ff & \multicolumn{8}{|c|}{ Ref. } \\
\hline $\begin{array}{l}\text { Dominant } \\
(\mathrm{FF}+\mathrm{Ff}) \mathrm{vs} \text {. ff }\end{array}$ & $0.33(0.09-1.2)$ & 0.10 & $0.33(0.09-1.2)$ & 0.10 & $0.29(0.071 .2)$ & 0.08 & $0.41(0.08-2)$ & 0.28 \\
\hline $\begin{array}{l}\text { Recessive FF } \\
\text { vs. (Ff+ff) }\end{array}$ & $1.2(0.6-2.4)$ & 0.52 & $1.3(0.6-2.5)$ & 0.48 & $1(0.5-2.1)$ & 0.97 & $1(0.5-2.1)$ & 0.10 \\
\hline \multicolumn{9}{|l|}{ Femoral Neck } \\
\hline \multicolumn{9}{|l|}{ Additive } \\
\hline $\mathrm{FF}$ & $1.5(0.4-5.9)$ & 0.6 & $1.1(0.3-4.7)$ & 0.86 & $0.9(0.2-4)$ & 0.94 & $1(0.2-4.6)$ & 0.9 \\
\hline $\mathrm{Ff}$ & $0.8(0.4-1.7)$ & 0.6 & $0.8(0.4-1.7)$ & 0.63 & $0.6(0.2-1.2)$ & 0.17 & $0.6(0.3-1.5)$ & 0.3 \\
\hline ff & \multicolumn{8}{|c|}{ Ref. } \\
\hline $\begin{array}{l}\text { Dominant } \\
(\mathrm{FF}+\mathrm{Ff}) \text { vs. ff }\end{array}$ & $0.6(0.2-2.5)$ & 0.53 & $0.8(0.2-3.3)$ & 0.8 & $0.9(0.2-3.6)$ & 0.8 & $0.9(0.2-3.9)$ & 0.9 \\
\hline $\begin{array}{l}\text { Recessive FF } \\
\text { vs. }(\mathrm{Ff}+\mathrm{ff})\end{array}$ & $1(0.5-2.1)$ & 0.8 & $1.1(0.6-2.2)$ & 0.7 & $1.6(0.8-3.3)$ & 0.2 & $1.4(0.7-3.1)$ & 0.4 \\
\hline \multicolumn{9}{|c|}{ BsmI, N = 218 } \\
\hline \multicolumn{9}{|l|}{ Lumbar spine } \\
\hline \multicolumn{9}{|l|}{ Additive } \\
\hline BB & $0.9(0.3-2.5)$ & 0.8 & $0.9(0.4-2.4)$ & 0.8 & $1(0.3-3)$ & 0.9 & $0.9(0.3-2.9)$ & 0.9 \\
\hline $\mathrm{Bb}$ & $1.5(0.7-3.3)$ & 0.3 & $1.4(0.8-3.2)$ & 0.3 & $1.6(0.7-3.7)$ & 0.3 & $1.3(0.6-3.2)$ & 0.5 \\
\hline $\mathrm{bb}$ & \multicolumn{8}{|c|}{ Ref. } \\
\hline $\begin{array}{l}\text { Dominant } \\
(\mathrm{BB}+\mathrm{Bb}) \mathrm{vs} \text {. } \\
\text { bb }\end{array}$ & $1.3(0.6-2.8)$ & 0.5 & $1.3(0.6-2.8)$ & 0.5 & $1.4(0.6-3.2)$ & 0.4 & $1.2(0.5-2.7)$ & 0.6 \\
\hline $\begin{array}{l}\text { Recessive BB } \\
\text { vs. (B+bb) }\end{array}$ & $0.7(0.2-1.7)$ & 0.4 & $0.7(0.2-1.7)$ & 0.4 & $0.7(0.3-1.9)$ & 0.5 & $0.8(0.3-2.1)$ & 0.6 \\
\hline \multicolumn{9}{|l|}{ Femoral Neck } \\
\hline \multicolumn{9}{|l|}{ Additive } \\
\hline BB & $2.3(0.8-6.4)$ & 0.1 & $2.3(0.8-6.6)$ & 0.1 & $2.9(1-9)$ & 0.056 & $3.2(1-10)$ & 0.049 \\
\hline $\mathrm{Bb}$ & $2.5(1-6)$ & 0.035 & $2.8(1.1-6.8)$ & 0.021 & $3.3(1.3-8.6)$ & 0.013 & $3.7(1.3-10)$ & 0.011 \\
\hline bb & \multicolumn{8}{|c|}{ Ref. } \\
\hline $\begin{array}{l}\text { Dominant } \\
(\mathrm{BB}+\mathrm{Bb}) \mathrm{vs} \text {. } \\
\mathrm{bb}\end{array}$ & $2.5(1-5.6)$ & 0.033 & $2.7(1.1-6.2)$ & 0.023 & $3.2(1.2-8)$ & 0.012 & $3.5(1.3-9.3)$ & 0.012 \\
\hline $\begin{array}{l}\text { Recessive BB } \\
\text { vs. }(\mathrm{BB}+\mathrm{bb})\end{array}$ & $1.2(0.5-2.7)$ & 0.6 & $1.2(0.5-2.7)$ & 0.7 & $1.3(0.5-3.1)$ & 0.5 & $1.3(0.5-3.2)$ & 0.5 \\
\hline $\begin{array}{l}\text { Over } \\
\text { dominant } \\
\text { Bb vs. (BB + } \\
\text { bb) }\end{array}$ & $0.57(0.29-1.1)$ & 0.1 & $0.52(0.25-1)$ & 0.066 & $0.49(0.23-1)$ & 0.059 & $0.46(0.21-1)$ & 0.053 \\
\hline
\end{tabular}

Abbreviations: VDR, vitamin D receptor; BMD, bone mineral density; BMI, body mass index; OR, odds ratio.

${ }^{a}$ According to the International Society for Clinical Densitometry (ISCD) guideline in additive, dominant and recessive models with adjustment for confounding factors. Adjustment was done in 3 models. Model 1 was adjusted for age and sex, model 2 for age, sex and BMI, and model 3 was adjusted for age, sex, BMI and the tanner stage of puberty.

${ }^{b}$ P values less than 0.05 were considered statistically significant.

tistically significant. Similarly, a higher BMD in individuals heterozygote for FokI (Ff genotype) was also reported by a previous study (29). In line with the results of the current study, no significant association was detected between FokI polymorphism and total body BMD in Danish or Lebanese girls (30).
In contrast to our findings, Ames et al. determined the impact of the VDR FokI genotype on BMD in children aged 7.5 - 12 years (6); indicating the association of ff genotype with higher BMD (2). Furthermore, in another study on prepubertal girls, Ferrari showed the relationship between the FF genotype and markedly decreased BMD (31). 


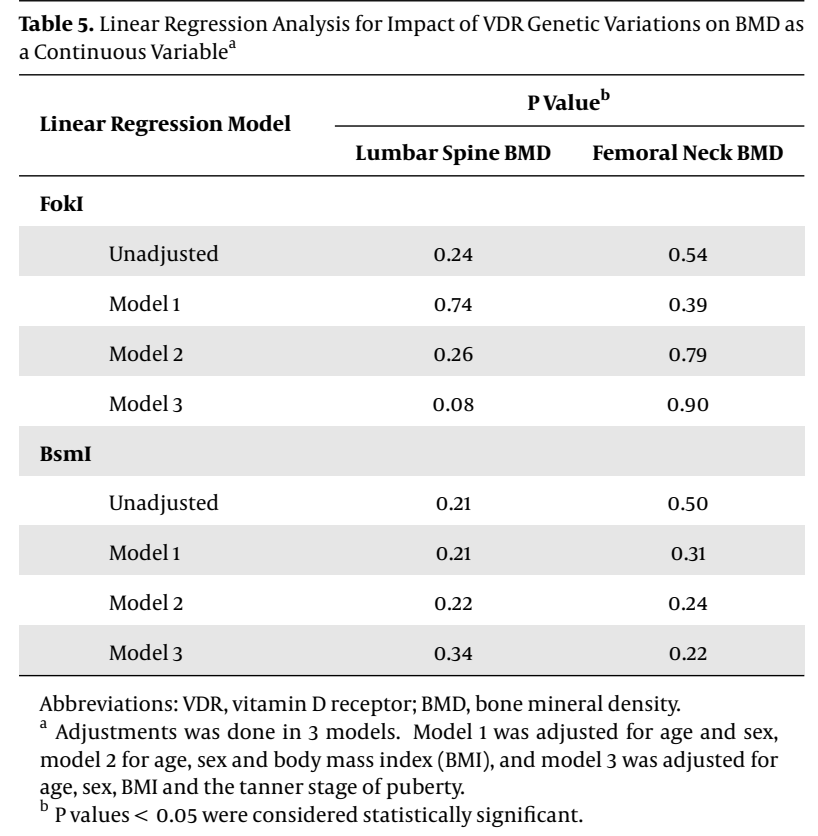

In the present study, no significant link was found between VDR FokI and height, in healthy Iranian children and adolescents; while Jakubowska-Pietkiewicz et al. (31) concluded that occurrence of the F allele in FokI polymorphism of the VDR receptor gene leads to an increase in body height.

In the current study, we did not observe any significant association of FokI with lumbar spine, neck, inter and total femur Z-scores; while Jakubowska-Pietkiewicz et al. revealed that in children with a Z-score between -1.0 and -2.0, the $f$ allele was related to higher bone mass (31). For FokI, in the unadjusted model and adjusted models, no significant association with BMD Z-scores was found. It seems that confounding factors (age, sex, BMI, and puberty) did not correlate with changes in BMD Z-score in Iranian children and adolescents.

In this study, we also examined the association between VDR BsmI polymorphisms and anthropometry, biochemical parameters and BMD in healthy children and adolescents. Variations in 3' untranslated region (UTR) of VDR (BsmI) sequence can change the mRNA steadiness and protein translation efficacy (32).

Also, we did not discover a significant association between VDR BsmI and serum levels of vitamin D, calcium, phosphorus, cholesterol, TG, and HDL. In addition, no significant correlation was observed between VDR BsmI and anthropometric characteristics (height and weight) in the current study. In a study by van der Sluis et al., an association between haplotypes assembled of the BsmI, ApaI, and TaqI polymorphisms, and height and vertebral body width was reported in Caucasian children and young adults (21). Association of VDR BsmI with BMD showed controversial results. In our study, we found a significant association between VDR BsmI ((Bb vs. bb) and (BB+Bb vs. bb)) and femoral neck Z-score. The BB genotype showed a higher risk for lower femoral neck Z-score in comparison with the bb genotype. Recently, a correlation of the B allele with BMD was described in two meta-analyses conducted by Thakkinstian et al. (15). Sainz et al. reported that femoral and vertebral bone density was higher in girls with bb genotypes than those with $\mathrm{BB}$ (33). Conversely, a longstanding study of Norwegian children found no effect of the BsmI genetic variants on BMD in children or adolescents. Similarly, Willing's team did not observe any statistically significant connection between BsmI VDR polymorphism and bone mass, in 428 healthy children aged 4.5 - 6.5 years (34). In the unadjusted model, model 1 and model 2, no significant association between BsmI (bb vs. BB) and femoral neck Z-score was observed; while in model 3, a slightly significant difference was observed. It seems that age, sex, BMI and puberty had a major effect on femoral neck Z-score; so that when these factors entered the model, an alteration in $\mathrm{P}$ value occurred. We concluded that BsmI site polymorphism is independently related to femoral neck Z-score, when adjusted for age, sex, BMI, and puberty. Comparing $\mathrm{Bb}$ vs. bb reveals a significant association in all 4 models; meaning that, BsmI is independently correlated with change in neck Z-score. In VDR BsmI, the Bb genotype is associated with the lower neck BMD Z-score risk in Iranian children and adolescents. Analysis under over dominate model showed no significant effect of heterozygosity. In the additive model we found that individual with Bb genotype had higher risk for lower femoral neck Z-score when compared to bb genotype, and in the dominant model, we observed that $\mathrm{Bb}+\mathrm{BB}$ group showed this effect when compared to the reference genotype (bb). On the other hand the BB group showed significant increased risk (OR 3.2, 95\% $\mathrm{CI}=1-10)$ under additive model and after adjustment for age, sex, BMI and the Tanner stage of puberty, result in favour of suggesting B allele as the risk allele..

Our study had some limitations. Because of the relatively small sample size, statistical power to detect associations of VDR variants with the risk of hyperlipidemia was limited. Subjects enrolled in the present study were selected from a cohort study from the south of Iran and may not represent the general population of Iranian children.

The difference between the results of our investigation and other studies, may be due to ethnic variations and diversity in geographical and environmental conditions of the studied populations. The limitation of our study was the small sample size; increasing the sample size lowers the variance in the results and increases the power of the 
experiment. Other interacting factors such as physical activity, diet and environmental factors, besides VDR polymorphisms, are important in bone mass acquisition; thus, it is recommended that they are considered in future studies.

\subsection{Conclusions}

$\mathrm{Bb}$ genotype of VDR gene BsmI site polymorphism (rs1544410) is associated with an elevated risk of low BMD in Iranian children and adolescents. Differences in the results of our study and some previous studies, regarding the association of VDR polymorphisms and BMD, may be attributed to ethnic variations.

\section{Footnotes}

Authors' Contribution: All of the Authors make substantial contributions to conception and design, and/or acquisition of data, and/or analysis and interpretation of data; drafting the article or revising it, and give final approval of the version to be submitted and any revised version.

Conflict of Interests: It is not declared by the authors.

Funding/Support: This study was funded by the Shiraz University of Medical Sciences (grant number: 33-10358).

\section{References}

1. Farr JN, Khosla S. Skeletal changes through the lifespan-from growth to senescence. Nat Rev Endocrinol. 2015;11(9):513-21. doi: 10.1038/nrendo.2015.89. [PubMed: 26032105]. [PubMed Central: PMC4822419].

2. Ames SK, Ellis KJ, Gunn SK, Copeland KC, Abrams SA. Vitamin D receptor gene Fok1 polymorphism predicts calcium absorption and bone mineral density in children. J Bone Miner Res. 1999;14(5):740-6. doi: 10.1359/jbmr.1999.14.5.740. [PubMed: 10320522].

3. Tantawy AA, El-Bostany EA, Matter RM, El-Ghoroury EA, Ragab S. Predictors of bone disease in Egyptian prepubertal children with beta-thalassaemia major. Arch Med Sci. 2010;6(4):584-91. doi: 10.5114/aoms.2010.14472. [PubMed: 22371804]. [PubMed Central: PMC3284075]

4. Valdivielso JM, Fernandez E. Vitamin D receptor polymorphisms and diseases. Clin Chim Acta. 2006;371(1-2):1-12. doi: 10.1016/j.cca.2006.02.016. [PubMed: 16563362].

5. Gennari L, Becherini L, Mansani R, Masi L, Falchetti A, Morelli A, et al FokI polymorphism at translation initiation site of the vitamin D receptor gene predicts bone mineral density and vertebral fractures in postmenopausal Italian women. J Bone Miner Res. 1999;14(8):1379-86. doi:10.1359/jbmr.1999.14.8.1379. [PubMed:10457270].

6. Katsumata K, Nishizawa K, Unno A, Fujita Y, Tokita A. Association of gene polymorphisms and bone density in Japanese girls. J Bone Miner Metab. 2002;20(3):164-9. doi: 10.1007/s007740200023. [PubMed: 11984699].

7. Lorentzon M, Lorentzon R, Nordstrom P. Vitamin D receptor gene polymorphism is associated with birth height, growth to adolescence, and adult stature in healthy caucasian men: A cross-sectional and longitudinal study. J Clin Endocrinol Metab. 2000;85(4):1666-70. doi:10.1210/jcem.85.4.6566. [PubMed: 10770213].
8. Dabirnia R, Mahmazi S, Taromchi A, Nikzad M, Saburi E. The relationship between vitamin D receptor (VDR) polymorphism and the occurrence of osteoporosis in menopausal Iranian women. Clin Cases Miner Bone Metab. 2016;13(3):190-4. doi: 10.11138/ccmbm/2016.13.3.190. [PubMed: 28228780]. [PubMed Central: PMC5318170].

9. Dehghan M, Pourahmad-Jaktaji R. The effect of some polymorphisms in vitamin $\mathrm{D}$ receptor gene in menopausal women with osteoporosis. J Clin Diagn Res. 2016;10(6):RC06-10. doi: 10.7860/JCDR/2016/17147.8006. [PubMed: 27504361]. [PubMed Central: PMC4963721].

10. Mohammadi Z, Keshtkar A, Fayyazbakhsh F, Ebrahimi M, Amoli MM, Ghorbani M, et al. Prevalence of osteoporosis and vitamin D receptor gene polymorphisms (FokI) in an Iranian general population based study (Kurdistan) (IMOS). Med J Islam Repub Iran. 2015;29:238. [PubMed: 26793629]. [PubMed Central: PMC4715426].

11. Ferrari S, Rizzoli R, Manen D, Slosman D, Bonjour JP. Vitamin D receptor gene start codon polymorphisms (FokI) and bone mineral density: Interaction with age, dietary calcium, and 3'-end region polymorphisms. J Bone Miner Res. 1998;13(6):925-30. doi 10.1359/jbmr.1998.13.6.925. [PubMed: 9626623].

12. Mohammadi Z, Fayyazbakhsh F, Ebrahimi M, Amoli MM, Khashayar $\mathrm{P}$, Dini $\mathrm{M}$, et al. Association between vitamin D receptor gene polymorphisms (Fok1 and Bsm1) and osteoporosis: A systematic review. J Diabetes Metab Disord. 2014;13(1):98. doi: 10.1186/s40200-014-0098-X. [PubMed: 25364703]. [PubMed Central: PMC4215021].

13. Yu XD, Shen XM, Xue MB, Yan $\mathrm{CH}$. Vitamin D receptor gene polymorphism and bone mineral density in 0-6-year-old Han children. J Bone Miner Metab. 2011;29(1):54-61. doi: 10.1007/s00774-010-0190-3. [PubMed: 20458603]

14. Bao L, Chen M, Lei Y, Zhou Z, Shen H, Le F. Association between vitamin $\mathrm{D}$ receptor BsmI polymorphism and bone mineral density in pediatric patients: A meta-analysis and systematic review of observational studies. Medicine (Baltimore). 2017;96(17). e6718. doi 10.1097/MD.0000000000006718. [PubMed: 28445285]. [PubMed Central: PMC5413250].

15. Thakkinstian A, D'Este C, Attia J. Haplotype analysis of VDR gene polymorphisms: A meta-analysis. Osteoporos Int. 2004;15(9):729-34. doi 10.1007/s00198-004-1601-x. [PubMed: 15057510].

16. Zintzaras E, Rodopoulou P, Koukoulis GN. BsmI, TaqI, ApaI and FokI polymorphisms in the vitamin D receptor (VDR) gene and the risk of osteoporosis: A meta-analysis. Dis Markers. 2006;22(5-6):317-26. [PubMed: 17264402]. [PubMed Central: PMC3851656].

17. Lorentzon $\mathrm{M}$, Lorentzon $\mathrm{R}$, Nordstrom P. Vitamin D receptor gene polymorphism is related to bone density, circulating osteocalcin, and parathyroid hormone in healthy adolescent girls. J Bone Miner Metab. 2001;19(5):302-7. doi: 10.1007/s0077410190302. [PubMed: 11498732].

18. Davies JH, Evans BA, Gregory JW. Bone mass acquisition in healthy children. Arch Dis Child. 2005;90(4):373-8. doi 10.1136/adc.2004.053553. [PubMed: 15781927]. [PubMed Central: PMC1720329].

19. Rahmadhani R, Zaharan NL, Mohamed Z, Moy FM, Jalaludin MY The associations between VDR BsmI polymorphisms and risk of vitamin D deficiency, obesity and insulin resistance in adolescents residing in a tropical country. PLoS One. 2017;12(6). e0178695. doi 10.1371/journal.pone.0178695. [PubMed: 28617856]. [PubMed Central: PMC5472260].

20. Jia F, Sun RF, Li QH, Wang DX, Zhao F, Li JM, et al. Vitamin D receptor BsmI polymorphism and osteoporosis risk: A meta-analysis from 26 studies. Genet Test Mol Biomarkers. 2013;17(1):30-4. doi: 10.1089/gtmb.2012.0267. [PubMed: 23134477].

21. van der Sluis IM, de Muinck Keizer-Schrama SM, Krenning EP, Pols HA, Uitterlinden AG. Vitamin D receptor gene polymorphism predicts height and bone size, rather than bone density in children and young adults. CalcifTissue Int. 2003;73(4):332-8. doi:10.1007/s00223-002-21302. [PubMed: 12874698]. 
22. Ashouri E, Meimandi EM, Saki F, Dabbaghmanesh MH, Omrani GR, Bakhshayeshkaram M. The impact of LRP5 polymorphism (rs556442) on calcium homeostasis, bone mineral density, and body composition in Iranian children. J Bone Miner Metab. 2015;33(6):651-7. doi: 10.1007/s00774-014-0624-4. [PubMed: 25515155].

23. International Society for Clinical Densitometry. 2013 ISCD official positions -pediatric. 2013. Available from: http://www.iscd.org/officialpositions/2013-iscd-official-positions-pediatric/.

24. Jeddi M, Dabbaghmanesh MH, Ranjbar Omrani G, Ayatollahi SM, Bagheri Z, Bakhshayeshkaram M. Body composition reference percentiles of healthy Iranian children and adolescents in southern Iran Arch Iran Med. 2014;17(10):661-9. [PubMed: 25305764].

25. Glocke M, Lang F, Schaeffeler E, Lang T, Schwab M, Lang UE. Impact of vitamin D receptor VDR rs2228570 polymorphism in oldest old. Kidney Blood Press Res. 2013;37(4-5):311-22. doi: 10.1159/000350159. [PubMed: 24060611].

26. Moran JM, Rodriguez-Velasco FJ, Roncero-Martin R, Rey-Sanchez P, Martinez M, Pedrera-Zamorano JD. The relationship between polymorphisms in the vitamin $\mathrm{d}$ receptor gene and bone mineral density in postmenopausal women. ISRN Gen. 2014;2014:1-7. doi: $10.1155 / 2014 / 549457$.

27. Keen RW, Egger P, Fall C, Major PJ, Lanchbury JS, Spector TD, et al. Polymorphisms of the vitamin D receptor, infant growth, and adult bone mass. Calcif Tissue Int. 1997;60(3):233-5. [PubMed: 9069157].

28. Riggs BL, Nguyen TV, Melton LJ 3rd, Morrison NA, O'Fallon WM, Kelly PJ, et al. The contribution of vitamin D receptor gene alleles to the determination of bone mineral density in normal and osteoporotic women. I Bone Miner Res. 1995;10(6):991-6. doi 10.1002/jbmr.5650100622. [PubMed: 7572325].
29. Nelson DA, Vande Vord PJ, Wooley PH. Polymorphism in the vitamin D receptor gene and bone mass in African-American and white mothers and children: A preliminary report. Ann Rheum Dis. 2000;59(8):62630. [PubMed: 10913060]. [PubMed Central: PMC1753219].

30. Sanwalka N, Khadilkar A, Chiplonkar S, Khatod K, Phadke N, Khadilkar V. Influence of vitamin D receptor gene Fok1 polymorphism on bone mass accrual post calcium and vitamin D supplementation. Indian J Pediatr. 2015;82(11):985-90. doi: 10.1007/s12098-015-1783-6. [PubMed: 25972288].

31. Jakubowska-Pietkiewicz E, Mlynarski W, Klich I, Fendler W, Chlebna-Sokol D. Vitamin D receptor gene variability as a factor influencing bone mineral density in pediatric patients. Mol Biol Rep. 2012;39(5):6243-50. doi: 10.1007/s11033-012-1444-z. [PubMed: 22422157].

32. Santos BR, Mascarenhas LP, Satler F, Boguszewski MC, Spritzer PM. Vitamin D deficiency in girls from South Brazil: A cross-sectional study on prevalence and association with vitamin $\mathrm{D}$ receptor gene variants. BMC Pediatr. 2012;12:62. doi: 10.1186/1471-2431-12-62. [PubMed: 22681928]. [PubMed Central: PMC3464685].

33. Sainz J, Van Tornout JM, Loro ML, Sayre J, Roe TF, Gilsanz V. Vitamin D-receptor gene polymorphisms and bone density in prepubertal American girls of Mexican descent. NEngl JMed.1997;337(2):77-82. doi: 10.1056/NEJM199707103370202. [PubMed: 9211676].

34. Willing MC, Torner JC, Burns TL, Janz KF, Marshall T, Gilmore J, et al. Gene polymorphisms, bone mineral density and bone mineral content in young children: The iowa bone development study. Osteoporos Int. 2003;14(8):650-8. doi: 10.1007/s00198-003-1416-1. [PubMed: 12879219] 